\title{
Kajian Hasil Pengujian X-Ray Diffraction (XRD) Dan Konstanta Dielektrik Membran Polimer Kitosan/PEG4000 dengan Lithium Triflat $\left(\mathrm{LiCF}_{3} \mathrm{SO}_{3}\right)$
}

\author{
Kartika Sari1 ${ }^{1}$, Agung Bambang Setio Utomo ${ }^{2}$, Parmin Lumban Toruan ${ }^{3 *}$, Ampala \\ Khoryanton ${ }^{4}$ \\ *e-mail: parmin.lt70@gmail.com \\ ${ }^{1}$ Jurusan Fisika FMIPA Universitas Jenderal Soedirman Purwoketo53123 \\ ${ }^{2}$ Departemen Fisika FMIPA Universitas Gadjah Mada Yogyakarta55281 \\ ${ }^{3}$ Program Studi Fisika FST Universitas PGRI Palembang 30252 \\ ${ }^{4}$ Departemen Teknik Mesin Politeknik Negeri Semarang50275
}

\begin{abstract}
Synthesis and characterization of chitosan/PEG4000 with $\mathrm{LiCF}_{3} \mathrm{SO}_{3}$ salt as a surfactant was carried out to determine crystalline size using X-Ray Diffraction (XRD) and dielectric constant using Electrochemical Impedance Spectroscopy (EIS). Fabrication of the electrolyte polymer membrane of chitosan/PEG4000 with $\mathrm{LiCF}_{3} \mathrm{SO}_{3}$ salt using the solution casting method. The result of XRD showed that the crystalline size of the chitosan, chitosan/PEG4000, and chitosan/PEG4000 electrolyte polymer membranes with $\mathrm{LiCF}_{3} \mathrm{SO}_{3}$ salt experienced a $2 \theta$ angle shift and formed a semicrystalline phase. The peak intensity increase occurred after chitosan was added with PEG4000 with $\mathrm{LiCF}_{3} \mathrm{SO}_{3}$ salt. The crystalline size obtained for the electrolyte polymer membrane of chitosan, chitosan/PEG4000, and chitosan/PEG4000 salt $\mathrm{LiCF}_{3} \mathrm{SO}_{3}$ was $4,002 \mathrm{~nm} ; 2,474 \mathrm{~nm}$, and $4,183 \mathrm{~nm}$. Meanwhile, the type of structure produced by chitosan, chitosan/PEG4000, and chitosan/PEG4000 electrolyte polymer membranes with $\mathrm{LiCF}_{3} \mathrm{SO}_{3}$ salt is a semicrystalline phase. The dielectric constant for solid electrolyte polymer membranes of chitosan/PEG4000, and chitosan/PEG4000 with $\mathrm{LiCF}_{3} \mathrm{SO}_{3}$ salt are 3,4 and 16,6 $\times 10^{3}$. Result of XRD and EIS show that chitosan/PEG4000 polymer membrane with $\mathrm{LiCF}_{3} \mathrm{SO}_{3}$ salt as a surfactant can be applied as an alternative to solid electrolyte polymer secondary batteries.
\end{abstract}

Keywords: chitosan, $\mathrm{PEG} 4000, \mathrm{LiCF}_{3} \mathrm{SO}_{3}$, crystalline size, dielectric constant

\begin{abstract}
ABSTRAK
Sintesis dan pengujian membran polimer elektrolit padat kitosan/PEG4000 dengan garam $\mathrm{LiCF}_{3} \mathrm{SO}_{3}$ sebagai surfaktan bertujuan untuk menentukan ukuran kristalin menggunakan X-Ray Diffraction (XRD) dan konstanta dielektrik menggunakan Electrochemical Impedance Spectroscopy (EIS). Pembuatan membran polimer elektrolit kitosan/PEG4000 dengan garam $\mathrm{LiCF}_{3} \mathrm{SO}_{3}$ menggunakan metode solution casting. Sampel yang digunakan dalam pengujian XRD dan EIS berbentuk membran polimer kitosan, kitosan/PEG4000 dan kitosan/PEG4000 dengan garam $\mathrm{LiCF}_{3} \mathrm{SO}_{3}$. Pengujian XRD menunjukkan ukuran kristalin untuk membran polimer elektrolit kitosan, kitosan/PEG4000, dan kitosan/PEG4000 dengan garam $\mathrm{LiCF}_{3} \mathrm{SO}_{3}$ mengalami pergeseran sudut $2 \theta$ dan membentuk fase semikristalin. Peningkatan puncak intensitas terjadi setelah kitosan ditambah dengan PEG4000 dengan $\mathrm{LiCF}_{3} \mathrm{SO}_{3}$. Ukuran kristalin yang diperoleh untuk membran polimer elektrolit kitosan, kitosan/PEG4000 dan kitosan/PEG4000 dengan garam $\mathrm{LiCF}_{3} \mathrm{SO}_{3}$ sebesar 4,002 nm; 2,474 nm dan 4,183 $\mathrm{nm}$. Sedangkan, jenis struktur yang dihasilkan membran polimer elektrolit kitosan, kitosan/PEG4000 dan kitosan/PEG4000 dengan $\mathrm{LiCF}_{3} \mathrm{SO}_{3}$ adalah fase semikristalin.
\end{abstract}




\begin{abstract}
Konstanta Dielektrik untuk membran polimer kitosan/PEG4000 dan kitosan/PEG4000 dengan garam $\mathrm{LiCF}_{3} \mathrm{SO}_{3}$ sebesar 3,4 dan 16,6 × 103. Hasil pengujian XRD dan EIS menunjukkan bahwa membran polimer kitosan/PEG4000 dengan $\mathrm{LiCF}_{3} \mathrm{SO}_{3}$ sebagai surfaktan dapat diaplikasi sebagai alternatif polimer elektrolit padat baterai sekunder.
\end{abstract}

Kata Kunci: kitosan, PEG4000, $\mathrm{LiCF}_{3} \mathrm{SO}_{3}$, ukuran kristalin, konstanta dielektrik

\section{PENDAHULUAN}

Salah satu biopolimer organik hasil deasetilasi kitin yang merupakan polimerisasi rantai glukosamin dan memiliki rumus molekul $\left[\mathrm{C}_{6} \mathrm{H}_{11} \mathrm{NO}_{4}\right]_{\mathrm{n}}$ dengan berat molekul 2,5 x $10^{5}$ Dalton yang sedang dikembangkan adalah kitosan. Kitosan memiliki sifat nontoksis, biodegradable, hidrofilik, dan terdiri gugus fungsi amina dan hidroksil (G. Abdullah dkk., 2017; Kartika dkk., 2020). Kitosan berbentuk serbuk berwarna putih kekuningan, tidak berbau dan tidak berasa. Penggunaan kitosan semakin menarik dikembangkan karena keberadaan gugus aminanya, sehingga kitosan dapat larut dalam asam yang dapat diaplikasi untuk sintesis membran polimer atau serat (Zhang dkk., 2014; Rochima dkk., 2016). Kemudian, ukuran partikel kitosan kecil sehingga mudah untuk dimodifikasi dengan material kimia lainnya (Liu dkk., 2011; Zhan dkk., 2014; Ker dkk., 2000).

Material kimia digunakan untuk modifikasi kitosan dalam penelitian ini adalah PEG (Polietilen Glikol). PEG4000 berbentuk serbuk, memiliki sifat dapat larut dalam air dan methanol (hidrofilik) (Barchuk, 2016). Adapun fungsi PEG4000 untuk mengontrol ukuran dan struktur pori membran. PEG4000 merupakan polimer dari etilen oksida yang memiliki perbedaan pada massa molekulnya (G. Abdullah dkk., 2017). PEG4000 juga dapat menghantarkan ion pada suhu kamar (Datta, 2007). Kitosan dan PEG4000 disintesis menjadi membran polimer padat.

Membran merupakan daerah tipis antara dua fase yang memilik lintasan tertentu sehingga memungkinkan fase atau komponen tertentu menembus lebih cepat dibandingkan dengan fase atau komponen lainnya di bawah pengaruh gaya penggerak (driving force) (Shukur dkk., 2013). Untuk meningkatkan kegunaan membran kitosan/PEG4000 maka digunakanlah garam lithium triflat $\left(\mathrm{LiCF}_{3} \mathrm{SO}_{3}\right)$ sebagai surfaktan.

Sintesis membran polimer yang dilakukan dengan mencampurkan serbuk kitosan dengan PEG4000 dan $\mathrm{LiCF}_{3} \mathrm{SO}_{3}$ bertujuan untuk meningkatkan sifat listrik membran polimer elektrolit yang akan diaplikasi baterai sekunder. Membran polimer elektrolit kemudian dilakukan pengujian menggunakan alat uji X-Ray Diffraction (XRD) dan Electrochemical Impedance Spectroscopy (EIS). Hasil uji XRD dan EIS dikaji ukuran kristalin dan konstanta dielektriknya.

\section{BAHAN DAN METODE}

Tempat penelitian dilakukan di dilakukan di Laboratorium Fisika Material Jurusan Fisika Universitas Jenderal Soedirman dan Laboratorium Kimia Organik Universitas Gadjah Mada dari bulan April sampai Agustus 2021.

Bahan-bahan yang digunakan dalam penelitian ini adalah kitosan, asam asetat $\left(\mathrm{CH}_{3} \mathrm{COOH}\right) \quad$ (Merck), Polietilen Glikol4000 (PEG4000) (Sigma-Aldrich) dan lithium triflat $\left(\mathrm{LiCF}_{3} \mathrm{SO}_{3}\right)$ (Sigma Aldrich). Sedangkan, alat yang digunakan adalah neraca Ohauss Galaxy TM 160, hot plate stirrer Thermo scientific model Cimarec 2, mikrometer skrup, desikator vacuum $200 \mathrm{~mm}$ Vitlab, cawan petri dan gelas ukur.

Peneiltian yang dilakukan terdiri dari 2 tahapan yaitu preparasi dan 
pengujian membran polimer kitosan, kitosan/PEG4000 dan kitosan/PEG4000 dengan garam $\mathrm{LiCF}_{3} \mathrm{SO}_{3}$. Tahapan preparasi pembuatan membran adalah dengan melarutkan serbuk kitosan sebanyak 1 gram ke dalam larutan asam asetat $\left(\mathrm{CH}_{3} \mathrm{COOH}\right)$ sebanyak $100 \mathrm{ml}$. Larutan kitosan diaduk menggunakan magnetik stirrer dengan variasi kecepatan dan suhu tertentu selama 15 menit hingga homogen. Setelah itu, PEG4000 dan garam $\mathrm{LiCF}_{3} \mathrm{SO}_{3}$ ditambahkan ke dalam larutan kitosan $1 \%$ sambil distirrer selama 1 jam hingga larutan kitosan/PEG4000/LiCF $\mathrm{SO}_{3}$ homogen. Kemudian, larutan kitosan/PEG $4000 / \mathrm{LiCF}_{3} \mathrm{SO}_{3}$ dicetak ke dalam cawan petri dan dikeringkan pada suhu $600 \mathrm{C}$ selama 2 hari menggunakan dried box. Membran kitosan, kitosan/PEG 4000 dengan garam $\mathrm{LiCF}_{3} \mathrm{SO}_{3}$ yang sudah kering dan siap dilakukan pengujian menggunakan X-Ray Diffraction (XRD) dan Electrochemical Impedance Spectroscopy (EIS).

\section{HASIL DAN PEMBAHASAN}

\section{a. Hasil Uji XRD Membran Polimer Kitosan, Kitosan/PEG4000 dengan garam $\mathrm{LiCF}_{3} \mathrm{SO}_{3}$}

Membran polimer membran polimer kitosan, kitosan/PEG4000 dengan garam $\mathrm{LiCF}_{3} \mathrm{SO}_{3}$ yang digunakan dalam pengujian XRD seperti Gambar 1.

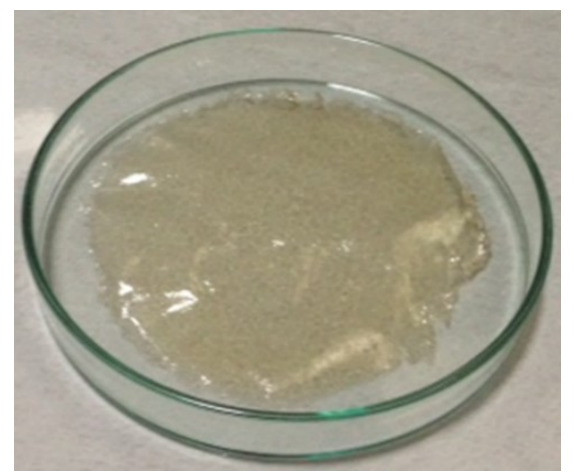

Gambar 1. Membran Polimer

Hasil pola difraksi XRD untuk membran kitosan, kitosan/PEG4000 dan
kitosan/PEG4000 dengan $\mathrm{LiCF}_{3} \mathrm{SO}_{3}$ pada Gambar 2 dan Gambar 3.

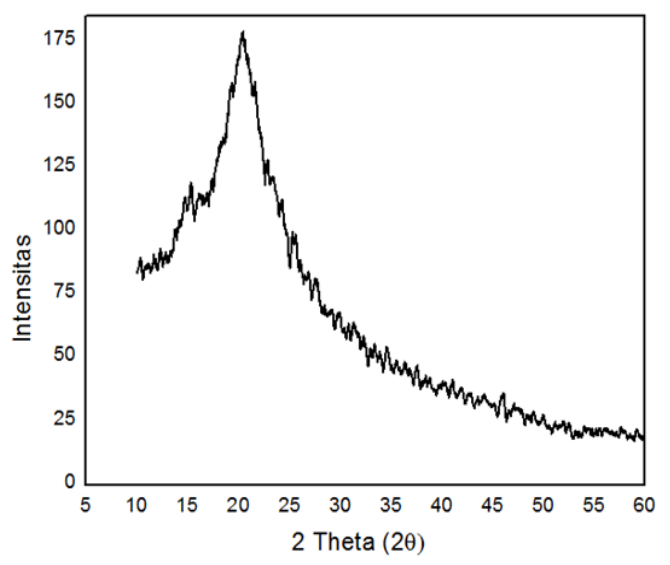

Gambar 2 Pola Difraksi Membran Polimer Kitosan

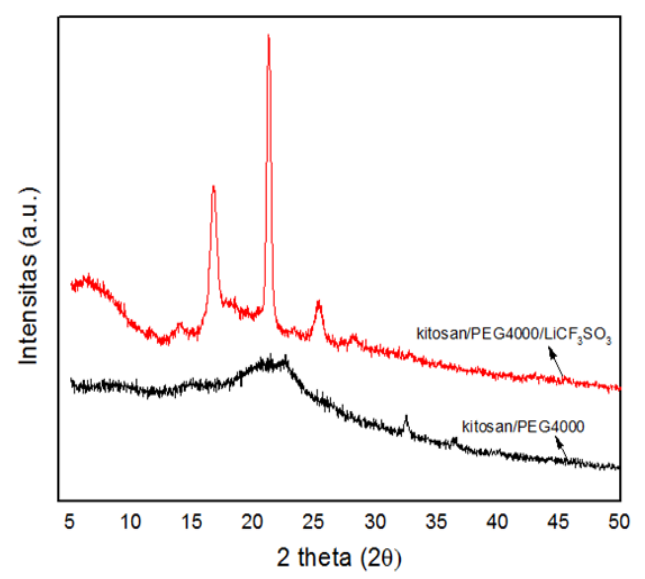

Gambar 3. Pola XRD Membran Polimer Kitosan/PEG4000,dan

Kitosan/PEG4000 dengan garam $\mathrm{LiCF}_{3} \mathrm{SO}_{3}$

Gambar 2 menunjukkan pola difraksi membran polimer kitosan. Puncak tertingi membran polimer kitosan berada di sudut, $2 \theta=21,45^{\circ}$ dan membentuk fase semikristalin. Sedangkan, Gambar 3 menunjukkan membran polimer kitosan/PEG4000 mengalami penurunan intensitas dan terjadi pelebaran puncak pada sudut $23,45^{\circ}$ dan membentuk fase amorf. Membran kitosan/PEG4000 dengan garam $\mathrm{LiCF}_{3} \mathrm{SO}_{3}$ terbentuk dua puncak tajam di sekitar sudut $2 \theta=17,65^{\circ}$ dan $23,54^{0}$. 
Pergeseran pola difraksi terjadi akibatnya interaksi antara molekul kitosan dengan PEG4000 dan garam $\mathrm{Li}^{+}$ yang terkandung dalam $\mathrm{LiCF}_{3} \mathrm{SO}_{3}$ yang menyebabkan perubahan struktur fase membran polimer tersebut dari fase amorf ke fase semi kristalin. Perubahan fase tersebut ditunjukkan dengan terjadinya peningkatan nilai intesitas pada membran kitosan/PEG4000 dengan garam $\mathrm{LiCF}_{3} \mathrm{SO}_{3}$.

Ukuran kristalin dari membran kitosan, kitosan/PEG4000 dan kitosan/PEG4000 dengan garam $\mathrm{LiCF}_{3} \mathrm{SO}_{3}$ ditentukan menggunakan persamaan Scherrer yaitu :

$$
d=\frac{k \lambda}{\beta \cos \theta}
$$

Dengan $d$ adalah ukuran kristalin (nm). $k$ adalah konstanta scherrer $(=0,89-0,9)$. $\lambda$ adalah panjang gelombang sinar-X $(=$ $1,54 \mathrm{~nm})$ dan $\beta$ adalah lebar setengah puncak (FWHM) (rad). Hasil pengukuran ukuran kristalin untuk membran kitosan, membran kitosan/PEG4000 dan kitosan/PEG4000 dengan garam $\mathrm{LiCF}_{3} \mathrm{SO}_{3}$ seperti Gambar 4.

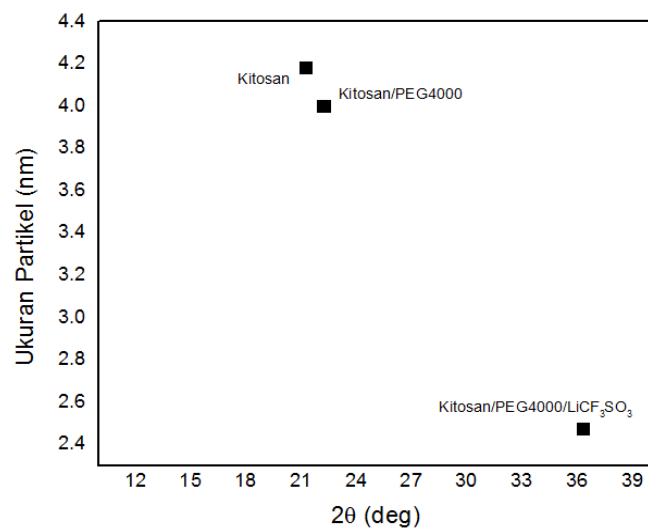

Gambar 4. Hubungan antara $2 \theta$ dengan ukuran kristalin

Ukuran kristalin terbesar yaitu sampel membran kitosan/PEG4000 dengan garam $\mathrm{LiCF}_{3} \mathrm{SO}_{3}$ sebesar 4,183 $\mathrm{nm}$ dan terkecil pada sampel membran kitosan/PEG4000 sebesar 2,474 nm.
Ukuran kristalin merupakan ukuran partikel yang memiliki efek pada struktur suatu kristal. Perubahan ukuran kristalin memberikan gambaran adanya ketidakmurnian atau cacat kisi pada struktur kristal. Peningkatan ukuran kristalin menunjukkan terjadinya interaksi antara ion $\mathrm{Li}^{+}$dengan kation dalam kitosan/PEG4000 sehingga terjadi tarik menarik dan membentuk gabungan antar partikel

\section{b. Hasil Uji EIS Membran kitosan, kitosan/PEG 4000 dengan garam $\mathrm{LiCF}_{3} \mathrm{SO}_{3}$}

Konstanta dielektrik membran polimer kitosan/PEG 4000 dan kitosan/PEG4000 dengan garam $\mathrm{LiCF}_{3} \mathrm{SO}_{3}$ seperti Gambar 5. Hasil uji EIS menunjukkan adanya peningkatan nilai konstanta dielektrik untuk membran kitosan/PEG4000, dan kitosan/PEG4000 dengan garam $\mathrm{LiCF}_{3} \mathrm{SO}_{3}$ sebesar 3,4 dan $16,6 \times 10^{3}$ (Gambar 5.).

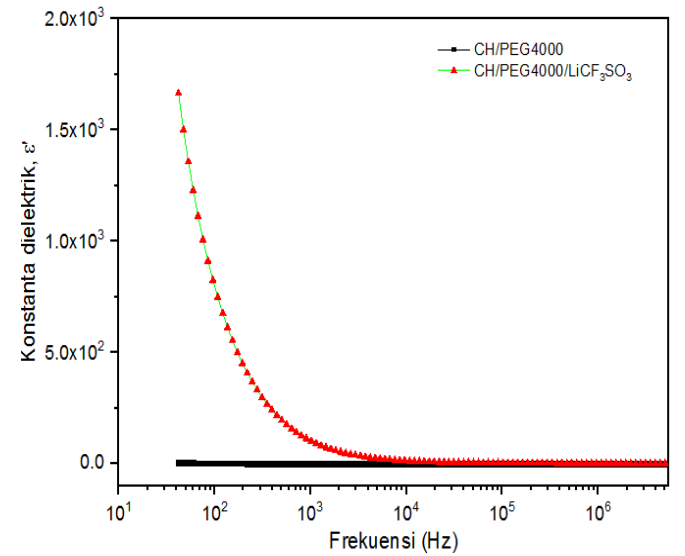

Gambar 5. Hasil uji EIS untuk Membran Kitosan/PEG4000 dan Kitosan/PEG4000 dengan garam $\mathrm{LiCF}_{3} \mathrm{SO}_{3}$

Fenomena dielektrik terjadi apabila medan listrik melewati media dieletrik maka kuat medan listrik yang dibutuhkan untuk melewati media tersebut dipengaruhi oleh kemampuan 
media tersebut terpolarisasi sebagai respon terhadap perubahan medan listrik.

\section{KESIMPULAN}

Hasil pengujian XRD untuk membran polimer kitosan, kitosan/PEG4000 dan kitosan/PEG4000 dan garam $\mathrm{LiCF}_{3} \mathrm{SO}_{3}$ menunjukkan bahwa terjadi pergeseran pada sudut $2 \theta$ sehingga terbentuk fase amorf, dan semikristalin. Ukuran kristalin yang dihasilkan mengalami penigkatan pada penambahan garam $\mathrm{LiCF}_{3} \mathrm{SO}_{3}$.

Pengujian EIS menghasilkan konstanta dilektrik yang meningkat pada membran polimer kitosan/PEG4000 dengan garam $\mathrm{LiCF}_{3} \mathrm{SO}_{3} . \quad$ Grafik konstanta dielektrik terjadi kenaikan drastis pada frekuensi rendah mengindikasikan adanya kontribusi dari akumulasi muatan pada daerah antar muka antara elektrolit dan elektroda.

Membran polimer kitosan, kitosan/PEG4000 dan kitosan/PEG4000 dengan garam $\mathrm{LiCF}_{3} \mathrm{SO}_{3}$ menghasilkan membran yang lebih fleksibel dan tidak bersifat higroskopis. Membran polimer kitosan/PEG4000 dengan garam $\mathrm{LiCF}_{3} \mathrm{SO}_{3}$ dapat juga digunakan sebagai bahan alternatif sintesis membran polimer elektrolit baterai sekunder.

\section{Ucapan Terima Kasih}

Penulis mengucapkan terima kasih kepada Kementrian Ristek/BRIN melalui Universitas Jenderal Soedirman melalui pendanaan BLU Skim Riset Peningkatan Kompetensi Tahun 2021.

\section{DAFTAR PUSTAKA}

A. Badawi, E. M. Ahmed, N. Y. Mostafa, F. Abdel-Wahab, dan S. E. Alomairy. (2017). Enhancement of the optical and mechanical properties of chitosan using $\mathrm{Fe}_{2} \mathrm{O}_{3}$ nanoparticles. J. Mater. Sci. Mater. Electron. 28(10877-10884).

A. Datta. (2007). Characterization of Polyethylene Glycol Hydrogels for Biomedical Applications, Thesis, University of Pune, India.

E. Rochima, Azhary, S.Y., Prata, R.I., Panatarani, C., dan Joni, I.M. (2016). Preparation and characterization of nano chitosan from crab shell waste by beads milling method. International conference on Food Science and Engineering. 193(1-6).

M. Barchuk. (2016). Structure and surface properties of chitosan/PEO/gelatin nanofibrous membrane. J. Polym. Res. 23(1-7).

MF., Shukur, Ithnin. R., dan Kadir. MFZ. (2013). Proton Conducting polymer electrolyte based on plasticitized chitosan/PEO blend and application in electrochemical devices. Optical Materials. 35 (1834-1841).

O. G. Abdullah, R. R. Hanna dan Y. A. K. Salman. (2017). Structural, optical, and electrical characterization of chitosan: methylcellulose polymer blends based film. J. Mater. Sci. Mater. Electron. 28(10283-10294).

S. Kartika, BSU.Agung, A. Kamsul, Roto, K. Evvy, Y. Evi, dan E. Suharyadi. (2020). Effect of Milling Time on the Microstructure and Dielectric Properties of Chitosan Nanopowder. International Journal of Nanoelectronic and Materials. 13 (1-8).

S. Kartika, E. Suharyadi, Roto, dan A. Kamsul. (2018). Microstructures and Functional Group Properties of Nano-Sized Chitosan Prepared by Ball Milling. Material Science Forum. 948(192-197).

T.Y., Liu, Ma, Y., Yu, S.F., Shi, J., dan Xue, S. (2011). The effect of ball milling treatment on structure and porosity of maize starch granule. 
Kajian Hasil Pengujian,...Kartika S., Agung B.S.U., Parmin L.T. dan Ampala K.,...Sainmatika,...Volume $18, \ldots$ No.2,...Desember $2021, \ldots 169-174$

Innovative Food Science and Emerging Technologies. 12(586593).

W.L., Ker, Ward, SDW., McWatters, KH., dan Resurreccion, AVA. (2000). Effect of milling and particle size on functionality and physicochemical properties of cowpea flour. American Association of Cereal Chemists Inc. Publication, 77(213-219).

W., Zhan, Zhang, J., dan Xia, W. (2014). Effect of ball milling treatment on physicochemical and structural properties of chitosan. International Journal of Food Properties. 17(26-37). 